\title{
COMPETÊNCIAS EMPREENDEDORAS E SUA RELAÇÃO COM O DESEMPENHO ENTRE OS MICRO E PEQUENOS EMPREENDEDORES DA CIDADE DE MONTES CLAROS - MG
}

\begin{abstract}
Aline Soares Ferreira ${ }^{1}$ Pablo Peron De Paula ${ }^{1}$ Felipe Froes Couto ${ }^{1}$

Simarly Maria Soares ${ }^{1}$
\end{abstract}

${ }^{1}$ Universidade Estadual de Montes Claros 


\section{COMPETÊNCIAS EMPREENDEDORAS E SUA RELAÇÃO COM O DESEMPENHO ENTRE OS MICRO E PEQUENOS EMPREENDEDORES DA CIDADE DE MONTES CLAROS - MG}

Resumo: O presente artigo tem como objetivo identificar as principais competências vinculadas ao perfil dos Empreendedores de Micro e Pequenas Empresas da cidade de Montes Claros MG a partir das características empreendedoras elencadas por McClelland (1972). Esta pesquisa classifica-se como quantitativa, de caráter descritivo, utilizando-se de levantamento de dados por meio de uma survey de corte transversal (cross-sectional) com 215 respondentes. Os dados da pesquisa revelam que o conjunto de realização é o mais presente entre os respondentes, indicando que a questão da execução das tarefas e atividades ainda recaem sobremaneira sobre os empreendedores, de modo que a sua capacidade de planejamento e de exercício de poder, delegando e coordenando tarefas e funções, saem prejudicadas. Também foi identificado que existe uma correlação positiva entre todas as competências, o que dá indícios de que as competências aumentam simultaneamente nos agentes empreendedores.

\section{Palavras-chave: Competências empreendedoras. Desempenho. Microempreendedor.}

\section{$1 \quad$ Introdução}

O empreendedorismo é fundamental não apenas para o desenvolvimento econômico, mas também por sua abrangência ao que se refere à concepção de mudanças na estrutura do negócio e da sociedade (HISRICH; PETERS, 2004). Em sua obra clássica de 1911, Teoria do Desenvolvimento Econômico, Schumpeter defende que os empreendedores são a força motriz do crescimento econômico, ao introduzir no mercado inovações que tornam obsoletos os produtos e as tecnologias existentes.

Contudo, independente da motivação para manter ou criar empreendimentos, é necessário conduzi-los de forma eficiente para obter sucesso. Para isso, Dias, Nardelli e Vilas Boas (2008) sugerem que os empreendedores precisam de uma ampla variedade de habilidades sociais, as quais envolvem um conjunto de competências que permitem aos indivíduos interagirem uns com os outros. Desse modo, Bittencourt (2005) enfatiza que o desenvolvimento de competências possibilita que as práticas organizacionais sejam direcionadas para uma gestão mais efetiva e propícia à estratégia competitiva.

O crescimento do espírito empreendedor tem feito aumentar a quantidade de empresas por todo o país e, dentre elas, as que mais têm demonstrado grande participação da economia nacional são as Micro e Pequenas Empresas (MPEs). O Serviço Brasileiro de Apoio às Micro e Pequenas Empresas (SEBRAE, 2014) destaca que as MPEs têm resultado numa contribuição relevante na economia brasileira, tanto no aumento do Produto Interno Bruto (PIB), quanto na geração de emprego e renda, trazendo assim, benefícios para a população. Além disso, as MPEs também contribuem para a arrecadação de tributos a serem revertidos em serviços e investimentos de interesse da população.

No contexto das MPEs, uma cidade que merece destaque no estado de Minas Gerais é o município de Montes Claros, que passou nos últimos anos por constante crescimento e expansão econômica. De acordo a JUCEMG (2019), nos últimos 5 anos, houve um aumento de 
16\% de empresas com este enquadramento. Segundo dados da Fundação João Pinheiro (FJP, 2015), Montes Claros representa o oitavo maior PIB de Minas Gerais, se caracterizando como polo socioeconômico regional. Em relação ao Norte de Minas, é a cidade de maior PIB, possuindo uma participação de 37,84\% na mesorregião, sendo o principal centro urbano de referência da população. Conforme dados da JUCEMG (2019), em Montes Claros, há um total de 33.320 empresas ativas, destas 96\%, são MPEs.

Diante da importância do empreendedorismo no contexto socioeconômico, e considerando as competências dos empreendedores como fundamental para o sucesso dessas empresas, indaga-se: quais são as competências vinculadas ao perfil dos empreendedores das Micro e Pequenas Empresas da cidade de Montes Claros - MG?

Assim, o presente artigo tem como objetivo identificar as principais competências vinculadas ao perfil dos Empreendedores de Micro e Pequenas Empresas da cidade de Montes Claros - MG. Especificamente, visa-se definir as principais competências empreendedoras a partir da abordagem teórica de McClelland (1972); mapear as características vinculadas aos empreendedores da cidade de Montes Claros - MG; identificar os principais gaps em relação às competências dos empreendedores e; relacionar as características dos empreendedores com o nível de satisfação com o desempenho da empresa.

\section{Referencial Teórico}

\section{1Empreendedorismo: Conceitos e Características}

$\mathrm{O}$ escritor e economista Richard Cantillon é considerado por muitos como um dos criadores do termo empreendedorismo. No século XVII, o empreendedor foi identificado como aquele que assumia riscos em negociações. No início do XX, Joseph Schumpeter, apresenta uma nova conotação ao termo empreendedor, definindo-o como alguém que possui atitudes inovadoras, que ao transformar recursos existentes em algo novo e original, promove o desenvolvimento e o crescimento econômico, instituindo o termo da destruição criativa (DORNELAS, 2014; LONGEN, 1997).

Autores como Dolabela (1999), Dornelas (2014) e Weber (1989) consideram os empreendedores como propulsores da economia, agente de mudanças e transformações. Suas características estão relacionadas à sua capacidade de iniciativa, de correr riscos, senso de oportunidade, criatividade, flexibilidade e pela capacidade de identificar as oportunidades (LEITE, 2001; SHAPERO, 1977; DRUCKER, 1987). O empreendedor também é uma pessoa competitiva para os negócios, que possui intuição para encontrar oportunidades, dedicado ao que gosta de fazer, flexível e inquieto. Possuem muitas ideias, alguns são estimulados pelo lucro rápido, outros pelo fato de gostar de criar (explorar seu potencial), e todos possuem uma característica em comum: são movidos em administrar seu próprio destino (AQUINO, 1987).

Em meio aos autores que estudaram o comportamento do empreendedor, destacase McClelland (1961). Para este autor, existem necessidades específicas marcantes que fazem parte da estrutura motivacional do indivíduo empreendedor, sendo estas: a necessidade de realização, que estimula o indivíduo a buscar objetivos que envolvem atividades desafiantes, com uma forte preocupação em fazer sempre melhor e mais eficiente, em perseguir o sucesso e o reconhecimento. A necessidade relacionada à afiliação, que ocorre quando o indivíduo se preocupa com suas relações emocionais positivas e afetivas com outros indivíduos. E, por fim, 
a necessidade de poder, na qual o indivíduo possui o desejo de obter o controle dos meios para influenciar outras pessoas.

\subsection{Competências}

Para McClelland (1973) a competência é uma característica implícita a uma pessoa que possui um desempenho superior na realização de uma tarefa ou em determinada situação. Nesta perspectiva, Dutra (2004), Boyatzis (1982) e Spencer Jr e Spencer (1993), definiram a competência como um conjunto de qualificações que a pessoa tem para realizar um trabalho com nível superior de performance.

Entretanto, nas décadas de 1980 e 1990, alguns autores contestaram esta definição de competência ligada apenas aos conhecimentos e habilidades das pessoas e associaram o conceito às suas ações e àquilo que elas propiciam, produzem e/ou entregam. Os defensores desta linha são, em sua maioria, de origem europeia, dentre eles, Le Boterf (2003). Na visão deste autor, "a competência requer uma instrumentalização em saberes e capacidades, mas não se reduz a essa instrumentalização" (p. 48). Para ele, as competências não residem apenas nos recursos (conhecimentos, capacidade cognitivas, entre outros) que uma pessoa possui, mas na mobilização desses recursos. "A competência é uma disposição para agir de modo pertinente em relação a uma situação específica" (LÊ BOTERF, 2003, p. 40). Ou seja, a competência é um "saber e agir". Dessa forma, não basta saber, mas é preciso saber como e quando aplicar este saber.

O termo competências foi se desenvolvendo rapidamente e surgiram diversas linhas de estudos na literatura. Dentre elas, Cheetham e Chivers (1996; 1998) e Gefroy e Tijou (2002), destacam três: A americana, cujo foco é os elementos comportamentais ou os atributos individuais, onde a competência é vista como um estoque de recursos do indivíduo. A Funcional (Inglaterra), nesta linha de estudo as competências, habilidades e atitudes são definidas mediante análise funcional do desempenho e das responsabilidades assumidas pelo indivíduo e as competências vinculadas aos objetivos organizacionais. E por fim, tem-se a Construtivista (França), nessa linha a competência é vista como um processo dinâmico reconhecido pelos resultados da ação se refere à competência prática.

\subsection{Competências Empreendedoras}

A competência empreendedora pode ser tratada como um conjunto de conhecimentos, habilidades e atitudes que possibilitam um indivíduo imprimir sua visão, estratégias e ações na criação de valor (tangíveis ou intangíveis) para a sociedade (ANTONELLO, 2005). Em consonância com essa afirmação, Snell e Lau (1994) defendem que a competência consiste em corpo de conhecimento, área ou habilidade, qualidades pessoais ou características, atitudes ou visões, motivações ou direcionamentos que podem, de diferentes maneiras, colaborar para o pensamento ou ação efetiva do negócio. Bittencourt (2005) enfatiza que o desenvolvimento de competências leva a vantagem competitiva, pois ele permite que as práticas organizacionais sejam direcionadas para uma gestão mais efetiva e propícia à estratégia competitiva.

Para Kets de Vries (1995); Man e Lau (2000) esse conjunto de características que definem a competência são influenciados por diversos fatores, como, experiência do indivíduo, sua cultura, capacitação e educação. Visando identificar tais competências empreendedoras e 
relacioná-las com as características dos empreendedores, alguns autores têm se preocupado em criar tipologias que possibilitem tal identificação. Nesse sentido, Lenzi (2008), reverenciou o trabalho desenvolvido por Cooley $(1990,1991)$, o qual destaca algumas características do comportamento do empreendedor, também chamadas de competências empreendedoras. Estas competências foram agrupadas em 3 conjuntos, sendo estes: realização, planejamento e poder, conforme exposto no Quadro 1.

Quadro 1 -Competências empreendedoras

\section{CONJUNTO DE REALIZAÇÃo}

\section{Busca de oportunidades e iniciativa (BOI)}

- Faz coisas antes de solicitado ou, antes de forçado pelas circunstâncias.

- Age para expandir o negócio a novas áreas, produtos ou serviços.

- Aproveita oportunidades fora do comum para começar um negócio, obter financiamentos, equipamentos, terrenos, local de trabalho ou assistência.

\section{Correr riscos calculados (CRC)}

- Avalia alternativas e calcula riscos deliberadamente.

- Age para reduzir os riscos ou controlar os resultados.

- Coloca-se em situações que implicam desafios ou riscos moderados.

Exigência de qualidade e eficiência (EQE)

- Encontra maneiras de fazer as coisas melhor e/ou mais rápido, ou mais barato

- Age de maneira a fazer coisas que satisfazem ou excedem padrões de excelência.

- Desenvolve ou utiliza procedimentos para assegurar que o trabalho seja terminado a tempo ou que o trabalho atenda a padrões de qualidade previamente combinados.

\section{Persistência (PER)}

- Age diante de um obstáculo.

- Age repetidamente ou muda de estratégia a fim de enfrentar um desafio ou superar um obstáculo.

- Assume responsabilidade pessoal pelo desempenho necessário para atingir as metas e objetivos.

\section{Comprometimento (COM)}

- Faz um sacrifício pessoal ou despende um esforço extraordinário para complementar uma tarefa.

- Colabora com os empregados ou se coloca no lugar deles, se necessário, para terminar um trabalho.

- Esforça-se para manter os clientes satisfeitos e coloca em primeiro lugar a boa vontade em longo prazo, acima do lucro em curto prazo.

\section{CONJUNTO DE PLANEJAMENTO}

Busca de informações (BDI)

- Dedica-se pessoalmente a obter informações de clientes, fornecedores e concorrentes.

- Investiga pessoalmente como fabricar um produto ou fornecer um serviço.

- Consulta os especialistas para obter assessoria técnica ou comercial.

\section{Estabelecimento de metas (EDM)}

- Estabelece metas e objetivos que são desafiantes e que tem significado pessoal.

- Define metas em longo prazo, claras e específicas.

- Estabelece metas em curto prazo, mensuráveis.

Planejamento e monitoramento sistemáticos (PMS)

- Planeja dividindo tarefas de grande porte em subtarefas com prazos definidos.

- Constantemente revisa seus planos levando em conta os resultados obtidos e mudanças circunstanciais. 
- $\quad$ Mantém registros financeiros e utiliza-os para tomar decisões.

\section{CONJUNTO DE PODER}

Persuasão e rede de contatos (PRC)

- Utiliza estratégias deliberadas para influenciar ou persuadir os outros.

- Utiliza pessoas chave como agentes para atingir seus próprios objetivos.

- Age para desenvolver e manter relações comerciais.

\section{Independência e autoconfiança (IEA)}

- Busca autonomia em relação a normas e controles de outros.

- Mantém seu ponto de vista, mesmo diante da oposição ou de resultados inicialmente desanimadores.

- Expressa confiança na sua própria capacidade de completar uma tarefa difícil ou de enfrentar um desafio.

Fonte: Adaptado de Lenzi (2008)

Verifica-se no quadro 1 que as competências estão divididas em três conjuntos de ações: realização, planejamento e poder. Segundo Elias (2001), o sucesso do negócio do empreendedor está vinculado a todas as competências empreendedoras supracitadas no Quadro 1 .

\subsection{Características das Micro e Pequenas Empresas (MPEs)}

As micro e pequenas empresas podem ser definidas por vários parâmetros segundo critérios adotados pelos agentes classificadores (IBGE, SEBRAE, BNDES) e o disposto na legislação vigente (BRASIL, 2006). A definição, mais comum e mais utilizada, é a que está presente na Lei Geral da Micro e Pequena Empresa a Lei Complementar 123/2006 que institui o Estatuto Nacional da Microempresa e da Empresa de Pequeno Porte, atualizadas pelas leis complementares 127/2007, 128/2008, 133/2009, 139/2011, 147/2014 e 155/2016.

Conforme o disposto no art. $3^{\circ}$ da lei 123 de 2006, consideram-se microempresas ou empresas de pequeno porte, a sociedade empresária, a sociedade simples, a empresa individual de responsabilidade limitada e o empresário a que se refere o art. 966 da Lei $\mathrm{n}^{\circ}$ 10.406, de 10 de janeiro de 2002 (Código Civil), devidamente registrados no Registro de Empresas Mercantis ou no Registro Civil de Pessoas Jurídicas, desde que possua receitas conforme incisos I e II:

I- no caso da microempresa, aufira, em cada ano-calendário, receita bruta igual ou inferior a $\mathrm{R} \$ 360.000,00$ (trezentos e sessenta mil reais); e

II- no caso de empresa de pequeno porte, aufira, em cada ano-calendário, receita bruta superior a $\mathrm{R} \$ 360.000,00$ (trezentos e sessenta mil reais) e igual ou inferior a $R \$ 4.800 .000,00$ (quatro milhões e oitocentos mil reais). (Redação dada pela Lei Complementar no 155, de 2016) (BRASIL, 2006).

Outra definição vem do Serviço Brasileiro de Apoio às Micro e Pequenas Empresas (SEBRAE) que utiliza como critério de classificação o número de empregados, conforme Tabela 1: 
Tabela 1 -Classificação do porte das empresas por número de empregados

\section{Indústria}

Micro: com até 19 empregados

Pequena: de 20 a 99 empregados

Média: 100 a 499 empregados

Grande: mais de 500 empregados

\section{Comércio e Serviços}

Micro: até 9 empregados

Pequena: de 10 a 49 empregados

Média: de 50 a 99 empregados

Grande: mais de 100 empregados

Fonte: SEBRAE/IBGE (2014)

Verifica-se que não há unanimidade sobre a definição das micro e pequenas empresas. Observa-se, na prática, uma variedade de critérios tanto por parte da legislação específica, quanto por parte de instituições financeiras oficiais e órgãos representativos do setor.

Segundo a Confederação Nacional do Comércio de Bens, Serviços e Turismo (CNC, 2017), as MPEs contribuem para a distribuição dos bens e serviços e, ao mesmo tempo, para a formação da riqueza numa sociedade. Por serem mais frágeis e sensíveis às oscilações do mercado, a conjuntura econômica impõe às MPEs situações delicadas, de risco e frequentemente adversas. Sendo assim, nos períodos de crise ou de expansão econômica, as MPEs necessitam do auxílio de leis, programas e políticas públicas que aliviem o ônus da necessidade de capital de giro. Necessitam também de investimento produtivo, de taxas de juros menores e custos financeiros diferenciados, de medidas que facilitem a gestão do negócio por meio da diminuição da burocracia, do número de exigências e de obrigações acessórias perante órgãos públicos, governo (municipal, estadual e federal) e junto ao fisco (CNC, 2017).

Por isso, e por serem especiais para a formação do tecido social de qualquer sociedade, as MPEs merecem e recebem tratamento legal diferenciado e favorecido. No Brasil, esse tratamento encontra-se estabelecido pela Constituição Federal no artigo 179. Destaca-se ainda sua relevância para a economia nacional, uma vez que elas representam, aproximadamente, $98,5 \%$ do total de empresas, além disso, são importantes fontes geradoras de emprego, sendo responsáveis por $70 \%$ dos empregos formais no setor privado do país(SEBRAE, 2017).

\section{Método}

Para alcançar os objetivos propostos, utilizou-se a pesquisa descritiva com corte transversal, pois pretende descrever as principais competências associadas ao perfil dos empreendedores das Micro e Pequenas Empresas da cidade de Montes Claros - MG. Esta pesquisa classifica-se como quantitativa, de caráter descritiva, utilizando-se de levantamento de dados por meio de uma survey de corte transversal (cross-sectional), conforme recomendado por Malhotra (2006).

A população deste estudo compreende os empreendedores de Micro e Pequenas Empresas (MPEs) da cidade de Montes Claros, localizada na região Norte de Minas Gerais. O critério para definição do universo de pesquisa foi o tamanho da empresa, ou seja, empresas enquadradas como MEI, ME e EPP do segmento de comércio, indústria e serviço.

De acordo com dados da Junta Comercial do Estado de Minas Gerais, JUCEMG (2019), Montes Claros possui 33.320 empresas ativas, dessas, 31.897 são MPEs, sendo esse o universo estudado. A amostra foi dimensionada para uma população finita com nível de confiança de $95 \%$ e um erro amostral de 7\%. Desta forma, são necessários 195 questionários válidos. Optou-se por enviar um número superior como margem de segurança, assim, foram 
enviados 2000 questionários por correio eletrônico e, aplicados 150 presencialmente, entre os dias 15/04/2019 e 30/05/2019. Foram obtidas 215 respostas, o que representa uma taxa de resposta de $10,75 \%$ e supera o número inicialmente dimensionado.

As variáveis de estudo seguiram o modelo de competências de Cooley (1990) e Spencer e Spencer (1993), adaptado por Lenzi (2008), por estes caracterizarem a abordagem mais completa e adequada sobre empreendedores.

O questionário foi composto, basicamente, por três seções. A primeira seção comporta uma mensagem de apresentação, com informações acerca da pesquisa a ser realizada e o caráter confidencial das respostas, bem como, agradecimentos à colaboração do participante. A segunda seção foi constituída de questões sobre características sociodemográficas dos empreendedores e da empresa. Na terceira seção, estão os dados referentes à identificação das competências vinculadas ao perfil do empreendedor, constituído de trinta afirmações.

Cada uma das competências identificadas por Cooley (1990), Spencer e Spencer (1993) e Dornelas (2003) é formada por três afirmações, totalizando assim as dez competências. Utilizou-se escala Likert de 5 pontos para verificar as competências vinculadas ao perfil do empreendedor. Assim, uma avaliação que configure o reconhecimento de competências em destaque deve ter média superior a 4 pontos (Lenzi, 2008).

Os dados obtidos foram tabulados por meio do software estatístico SPSS (Statistical Package for the Social Science). Inicialmente, foram realizadas análises exploratórias com o objetivo de identificar eventuais erros de digitação e a presença de missings. Após essa etapa, $100 \%$ dos questionários foram validados.

Foram realizados testes qui-quadrado de Pearson para verificar a associação entre as características dos empreendedores e o nível de satisfação com o seu desempenho. O nível de significância estatística utilizado foi de $5 \%(\mathrm{p} \leq 0,05)$. Realizou-se também a análise de correlação para verificar a associação entre as competências vinculadas ao perfil dos empreendedores de MPEs da cidade de Montes Claros - MG.

\section{Apresentação e Discussão dos Resultados}

Os resultados, expostos na Tabela 2, evidenciaram que a maioria dos respondentes pertence ao sexo masculino, $56,3 \%$. Constatou-se também que a faixa etária predominante é de 31 a 40 anos, que equivale a 34,4\% dos entrevistados. Em relação à escolaridade, verificou-se que o ensino médio prevalece entre os participantes, significando 53,9\% dos respondentes. Quanto ao segmento, observa-se que o comércio representa 50,5\% dos pesquisados. Por fim, em relação ao tempo de atuação, constatou-se que a maior parte das empresas possuem menos de 5 anos, representando 68,2\%.

É possível constatar que existe associação significativa entre as varáveis sexo e satisfação do empreendedor com o desempenho da empresa. A proporção dos homens satisfeitos é significativamente maior do que as mulheres. Esse fato pode estar relacionado às dificuldades que as mulheres encontram para compatibilizar o trabalho e a família. São raras as empreendedoras que têm uma separação entre o trabalho e a vida pessoal, ou a vida em família e, como consequência, geralmente o conflito trabalho-família é presente (GOMES; SANTANA, 2009; STROBINO; TEIXEIRA, 2014). 
Tabela 2 - Caracterização dos empreendedores x nível de satisfação com desempenho

\begin{tabular}{|c|c|c|c|c|c|c|c|c|}
\hline \multirow{3}{*}{ Variáveis } & \multirow{3}{*}{$\begin{array}{c}\text { Amostra } \\
\mathrm{n}(\%)\end{array}$} & \multicolumn{6}{|c|}{ Desempenho } & \multirow{3}{*}{$p^{*}$} \\
\hline & & \multicolumn{2}{|c|}{ Insatisfeito } & \multicolumn{2}{|c|}{ Indiferente } & \multicolumn{2}{|c|}{ Satisfeito } & \\
\hline & & $\mathrm{n}$ & $\%$ & $\mathrm{n}$ & $\%$ & $\mathrm{n}$ & $\%$ & \\
\hline Total & $215(100,0 \%)$ & 12 & 5,6 & 18 & 8,4 & 185 & 86 & \\
\hline Sexo & & & & & & & & 0,017 \\
\hline Feminino & $94(43,7 \%)$ & 10 & 10,6 & 7 & 7,4 & 77 & 81,9 & \\
\hline Masculino & $121(56,3 \%)$ & 2 & 1,7 & 11 & 9,1 & 108 & 89,3 & \\
\hline Idade (anos) & & & & & & & & 0,159 \\
\hline Até 30 anos & $43(20,0 \%)$ & 0 & 0,0 & 5 & 11,6 & 38 & 88,4 & \\
\hline De 31 a 40 & $74(34,4 \%)$ & 4 & 5,4 & 6 & 8,1 & 64 & 86,5 & \\
\hline De 41 a 50 & $57(26,5 \%)$ & 5 & 8,8 & 7 & 12,3 & 45 & 78,9 & \\
\hline Acima de 50 & $41(19,1 \%)$ & 3 & 7,3 & 0 & 0,0 & 38 & 92,7 & \\
\hline Escolaridade & & & & & & & & 0,619 \\
\hline Não alfabetizado & $4(1,9 \%)$ & 1 & 25 & 0 & 0 & 3 & 75 & \\
\hline Fundamental & $34(15,8 \%)$ & 1 & 2,9 & 2 & 5,9 & 31 & 91,2 & \\
\hline Médio & $116(53,9 \%)$ & 6 & 5,2 & 8 & 6,9 & 102 & 87,9 & \\
\hline Superior & $45(20,9 \%)$ & 3 & 6,7 & 6 & 13,3 & 36 & 80 & \\
\hline Pós-graduação & $16(7,5 \%)$ & 1 & 6,2 & 2 & 12,5 & 13 & 81,2 & \\
\hline Segmento & & & & & & & & 0,518 \\
\hline Comércio & $108(50,5 \%)$ & 7 & 6,5 & 9 & 8,3 & 92 & 85,2 & \\
\hline Indústria & $3(1,4 \%)$ & 0 & 0 & 1 & 33,3 & 2 & 66,7 & \\
\hline Serviço & $103(48,1 \%)$ & 5 & 4,9 & 7 & 6,8 & 91 & 88,3 & \\
\hline Tempo de atuação & & & & & & & & 0,046 \\
\hline Até 5 anos & $146(68,2 \%)$ & 4 & 2,7 & 14 & 9,6 & 128 & 87,7 & \\
\hline De 6 a 10 anos & $36(16,8 \%)$ & 5 & 13,9 & 1 & 2,8 & 30 & 83,3 & \\
\hline De 11 a 20 anos & $22(10,3 \%)$ & 1 & 4,5 & 1 & 4,5 & 20 & 90,9 & \\
\hline Acima de 20 anos & $10(4,7 \%)$ & 2 & 20 & 1 & 10 & 7 & 70 & \\
\hline
\end{tabular}

Fonte: Dados da Pesquisa (2019)

A análise permite, ainda, verificar que existe associação estatística significativa entre o tempo de atuação e o desempenho. Ou seja, o nível de satisfação com o desempenho da empresa varia de acordo com tempo de atuação da empresa. Esse fator pode estar relacionado aos estágios do ciclo de vida organizacional.

Para Lester, Parnell e Carraher (2003), o ciclo de vida organizacional apresenta cinco fases, sendo estas: Nascimento, Crescimento, Maturidade, Rejuvenescimento e Declínio. A fase de "nascimento" marca o início do desenvolvimento organizacional, a tomada de decisão é centralizada e está nas mãos de poucas pessoas ou de uma só. O ambiente organizacional é criado e ordenado pela própria organização e o foco nesta fase é identificar a viabilidade dos negócios. Na fase do "crescimento", as empresas buscam o crescimento, desenvolvem algumas formalizações estruturais e estabelecem suas competências. Neste estágio, algumas organizações crescem e prosperam, permitindo entrar na terceira fase (sucesso). Nesta fase do "sucesso/maturidade", as empresas têm estabilidade e eficiência como metas e uma estrutura mais burocrática é estabelecida. Na "renovação", as organizações desejam voltar para um período em que a colaboração e o trabalho de equipe fomentavam a inovação e a criatividade. A estrutura matricial é bastante utilizada e o processo de tomada de decisão é descentralizado. Nesta fase, as necessidades dos clientes são colocadas acima daquelas dos sócios. E, por último, tem-se a fase do "declínio", na qual as empresas estão começando a estagnar com a redução na participação nos mercados e com as linhas de produtos começando a se tornarem obsoletas, o que tende a iniciar sua morte. 
O fato de o nível de satisfação variar de acordo com o tempo de atuação da empresa pode estar relacionado ao ciclo de vida. As duas primeiras faixas de tempo de atuação provavelmente estão associadas às fases de nascimento e crescimento. $\mathrm{O}$ tempo de atuação de 11 a 20 anos pode estar associado a fase da maturidade, tendo em vista que a satisfação com o desempenho é alta. Já o tempo de atuação acima de 20 anos possivelmente está relacionado a fase do declínio. Verifica-se que a proporção de empreendedores satisfeitos nas primeiras fases é alta, tendo a maior prevalência na fase da maturidade e ocorrendo uma redução significativa na fase de declínio.

\section{Análise Descritiva das Competências Empreendedoras}

A Tabela 3 apresenta os valores descritivos dos escores das competências analisadas: valores mínimos, máximos, a média, mediana e o desvio padrão, que têm como objetivo resumir os dados para estudo. A média foi utilizada como medida-chave para as análises dos escores obtidos.

Tabela 3 - Medidas descritivas dos escores das competências analisadas

\begin{tabular}{lcccccc}
\hline & & & & & & \multicolumn{2}{c}{$\begin{array}{c}\text { Desvio } \\
\text { Padrão }\end{array}$} \\
\hline Busca de oportunidades e iniciativa & 215 & 1,00 & 5,00 & 3,68 & 3,67 & 0,98 \\
Correr riscos calculados & 215 & 1,00 & 5,00 & 3,93 & 4,00 & 0,86 \\
Exigência de qualidade e eficiência & 215 & 1,67 & 5,00 & 4,51 & 4,67 & 0,61 \\
Persistência & 214 & 2,33 & 5,00 & 4,51 & 4,67 & 0,58 \\
Comprometimento & 215 & 2,00 & 5,00 & 4,52 & 4,67 & 0,60 \\
Busca de informações & 215 & 1,00 & 5,00 & 3,96 & 4,17 & 0,92 \\
Estabelecimento de metas & 215 & 1,00 & 5,00 & 3,72 & 4,00 & 1,00 \\
Planejamento e monitoramento & 215 & 1,00 & 5,00 & 3,80 & 4,00 & 0,97 \\
sistemáticos & & & & & & \\
Persuasão e rede de contatos & 215 & 1,00 & 5,00 & 3,47 & 3,67 & 1,17 \\
Independência e autoconfiança & 215 & 1,00 & 5,00 & 4,07 & 4,33 & 0,87 \\
\hline
\end{tabular}

Fonte: Dados da Pesquisa (2019)

O instrumento de pesquisa permite verificar que, em ordem decrescente, os empreendedores apresentam as seguintes competências empreendedoras: Comprometimento; Exigência de Qualidade e Eficiência; Persistência e; Independência e Autoconfiança. A competência de maior destaque, Comprometimento, com média de 4,52, revela haver grande esforço do empreendedor para completar uma tarefa, fazendo qualquer coisa para manter o cliente. Em relação a essa competência, Deming (1998) e Juran (1997) salientam que o comprometimento é um dos fatores para o sucesso empresarial, porém ele deve ser conduzido com segurança, liderança e participação. Como evidenciado neste estudo, Man e Lau (2000) expõem que, para alcançar o sucesso, o empreendedor deve assumir pessoalmente o compromisso com o desempenho da empresa, deve estar disposto a sacrifícios e a mergulhar totalmente em seus empreendimentos.

Além do Comprometimento, destacam-se as competências de Exigência de Qualidade e Eficiência e a Persistência (PER). Constata-se que essas competências pertencem ao conjunto de realização proposto por McClelland (1972), que defende que a realização está 
na base do comportamento empreendedor. Para McClelland (1972), a necessidade de realização é desenvolvida a partir da cultura, das experiências e da aprendizagem. Sua hipótese básica também considera essa necessidade como responsável, em grande parte, pelo desenvolvimento econômico de uma região / país.

De acordo com proposta de Cooley (1990) e Spencer e Spencer (1993), adaptado por Lenzi (2008), as competências empreendedoras são agrupadas em três conjuntos distintos, a saber: planejamento, realização e poder. A Tabela 4 apresenta os valores descritivos dos escores dos conjuntos analisados. A média foi utilizada como medida-chave para as análises dos escores obtidos.

Tabela 4 - Conjunto de Competências Empreendedoras

\begin{tabular}{lcccccc}
\hline & $\mathrm{N}$ & Mínimo & Máximo & Média & Mediana & Desvio Padrão \\
\hline Realização & 215 & 1,80 & 5,00 & 4,23 & 4,33 & 0,52 \\
Planejamento & 215 & 1,33 & 5,00 & 3,83 & 3,89 & 0,78 \\
Poder & 215 & 1,33 & 5,00 & 3,77 & 3,83 & 0,84 \\
\hline
\end{tabular}

Fonte: Dados da Pesquisa (2019)

Realização foi o conjunto presente entre os empreendedores, com média de 4,23 pontos. O fato de o Poder ter sido apontado como um conjunto de competência menos expressiva, pode indicar que a capacidade de criar redes de contatos e influência (networking) não seja uma característica predominante entre os empreendedores. Isso é evidenciado em Rego e Leite (2002) que aponta que uma motivação elevada para o poder está ligada a atividades competitivas e ao interesse em atingir e manter prestígio e reputação.

\section{Correlação entre as Competências Empreendedoras}

A Tabela 5 mostra os resultados dos cálculos das correlações de Pearson entre as dez competências: busca de oportunidades e iniciativa; correr riscos calculados; exigência de qualidade e eficiência; persistência; comprometimento; busca de informações; estabelecimento de metas; planejamento e monitoramento sistemáticos; persuasão e rede de contatos e independência e autoconfiança.

Tabela 5 - Matriz de correlações entre as competências empreendedoras

\begin{tabular}{lcccccccccc}
\hline & BOI & CRC & EQE & PER & COM & BDI & EDM & PMS & PRC & IEA \\
\hline BOI & 1 & & & & & & & & & \\
CRC & 0,494 & 1 & & & & & & & & \\
EQE & 0,404 & 0,406 & 1 & & & & & & & \\
PER & 0,357 & 0,376 & 0,345 & 1 & & & & & & \\
COM & 0,385 & 0,221 & 0,352 & 0,457 & 1 & & & & & \\
BDI & 0,420 & 0,316 & 0,285 & 0,338 & 0,292 & 1 & & & & \\
EDM & 0,455 & 0,403 & 0,278 & 0,534 & 0,417 & 0,503 & 1 & & & \\
PMS & 0,363 & 0,299 & 0,388 & 0,305 & 0,349 & 0,427 & 0,492 & 1 & & \\
PRC & 0,409 & 0,301 & 0,297 & 0,328 & 0,308 & 0,393 & 0,406 & 0,368 & 1 & \\
IEA & 0,190 & $0,170^{*}$ & 0,249 & 0,299 & 0,278 & 0,235 & 0,301 & 0,218 & 0,345 & 1 \\
\hline
\end{tabular}

Fonte: Dados da Pesquisa (2019)

As análises desses resultados indicam que todas as variáveis estão positivamente correlacionadas, ou seja, possuem uma associação direta. Além do mais, todas as correlações 
são significativas ao nível de $99 \%$, exceto a correlação entre independência e autoconfiança (IEA) e correr riscos calculados (CRC), que é significativa ao nível de $95 \%$. Isso evidencia que o desenvolvimento de uma competência acarreta também o desenvolvimento de outras.

As competências empreendedoras com maior correlação pertencem aos conjuntos "Planejamento e Realização", sendo elas, o estabelecimento de metas (EDM) com a persistência (PER), com coeficiente de 0,534, evidenciando que, quanto mais um empreendedor estabelece metas, maior será a sua persistência. A segunda correlação mais forte faz parte do conjunto "Planejamento", sendo estas: estabelecimento de metas (EDM) e busca de informações (BDI), indicando que, quanto mais o empreendedor estabelece metas, mais ele está disposto a buscar informações.

Em face desses resultados, buscou-se verificar se existe uma relação entre o desempenho e as competências empreendedoras. Os resultados são apresentados na Tabela 6.

Tabela 6 - Correlações entre as Competências Empreendedoras e Desempenho

\begin{tabular}{c|c|c|c|c|c|c|c|c|c|c}
\hline & BOI & CRC & EQE & PER & COM & BDI & EDM & PMS & PRC & IEA \\
\hline Desempenho & $-0,134^{*}$ & $-0,032$ & 0,000 & $-0,048$ & $-0,072$ & $-0,019$ & $-0,086$ & $-0,056$ & 0,028 & $-0,054$ \\
\hline
\end{tabular}

Fonte: Dados da Pesquisa (2019)

A satisfação com desempenho possui uma correlação negativa, significativa ao nível de 95\%, apenas com a busca de oportunidades e iniciativa (BOI), apresentando um coeficiente de correlação de -0,134. Isso indica que quanto menor satisfação com o desempenho maior é a busca por oportunidade e iniciativa (BOI).

As demais competências tiveram correlações não significativas com o desempenho, sendo que a maioria delas foram correlações negativas e apenas uma correlação foi positiva, sendo esta, a competência de persuasão e rede de contatos (PRC).

\section{Conclusões}

A pesquisa permitiu identificar as principais competências vinculadas ao perfil dos Empreendedores de Micro e Pequenas Empresas da cidade de Montes Claros - MG. Os resultados demonstram que quatro das dez competências estão associadas ao perfil dos empreendedores, sendo estas o Comprometimento; Exigência de Qualidade e Eficiência; Persistência e; Independência e Autoconfiança.

Observou-se também que as competências empreendedoras mais presentes estão relacionadas ao comprometimento (COM), a exigência de qualidade e eficiência (EQE) e a persistência (PER), verifica-se ainda que essas características estão relacionadas ao conjunto de realização, como proposto por McClelland (1972), mostrando haver uma forte tendência dos empreendedores serem motivados pela busca de realização.

A análise dos dados também permitiu verificar que existe uma associação estatística significativa entre as variáveis, sexo e desempenho (satisfação), pois a proporção dos homens satisfeitos é significativamente maior, ao nível de $95 \%$ do que as mulheres. Ao relacionar também o tempo de atuação da empresa com o desempenho (satisfação), verificou-se que existe uma associação estatística significativa em relação ao nível de satisfação, podendo inferir que isso esteja relacionado ao ciclo de vida organizacional. 
O trabalho também consistiu na comparação entre os conjuntos de competências que são: realização, planejamento e poder. O resultado em questão evidenciou que o conjunto de realização foi o conjunto que obteve a maior média em relação aos demais conjuntos, apresentando 4,22 pontos. Verificou-se que o conjunto de poder foi o que obteve uma menor média, com 3,77 pontos. Vale ressaltar que segundo McClelland (1961) a necessidade de poder se expressa por intermédio da vontade da pessoa em manter o controle do ambiente e de outras pessoas exercendo influência sobre as elas.

Tais achados podem ser problematizados. Isso porque os dados da pesquisa revelam que o conjunto de realização é o mais presente entre os respondentes, indicando que a questão da execução das tarefas e atividades ainda recaem sobremaneira sobre os empreendedores, de modo que a sua capacidade de planejamento e de exercício de poder, delegando e coordenando tarefas e funções, saem prejudicadas. Isso é um indicativo de um perfil centralizador das funções operacionais e de gestão pelos empreendedores.

Por meio das correlações de Pearson, foi identificado que existe uma correlação positiva entre todas as competências, o que demonstra que as competências aumentam simultaneamente. As competências que obtiveram uma correlação mais forte foram o EDM (estabelecimento de metas) com a PER (persistência), ou seja, quanto mais o empreendedor planeja, maior é a sua persistência, ou vice-versa.

Também foi identificado uma correlação negativa significativa em relação à competência BOI (busca de oportunidades e iniciativa) e o desempenho, o que demonstra que estas variáveis aumentam em sentidos contrários, ou seja, quanto menor a satisfação com o desempenho, maior será a busca por oportunidades. Essa questão também pode ser problematizada, pois indica que, menos do que um desejo por inovar proativamente, os empreendedores pesquisados apresentam um perfil mais reativo, ou seja, empreendem em busca de sustentabilidade e rentabilidade. O que os motiva a sair da zona de conforto e buscar por novas possibilidades são os resultados negativos da empresa, não o desejo de se manter à frente da concorrência.

A análise dos dados em consonância com a fundamentação teórica possibilitou também identificar os gaps em relação às competências empreendedoras. Assim, foi evidenciado que as características que tiveram menor destaque foram: estabelecimento de metas (EDM), busca de oportunidades e iniciativa (BOI) e persuasão e rede de contatos (PRC).

Como limitação, essa pesquisa obteve um baixo índice de retorno dos questionários enviados aos empreendedores. O que ressalta um desinteresse dos empreendedores em oferecer informações e, em consequência, pode limitar o poder de extrapolação dos resultados desta pesquisa, reduzindo assim a força da análise. Destaca-se também que esta pesquisa é um trabalho transversal que possibilitou a análise do cenário atual das competências empreendedoras. Sugere-se então, que estudos futuros analisem longitudinalmente o desenvolvimento das competências empreendedoras.

Diante dos resultados, propõe-se que seja criado políticas públicas pelo município, por meio de parcerias entre o município, Sebrae, Universidades Públicas e Privadas, ACI, CDL, Sala Mineira do Empreendedor, entre outras, voltadas para desenvolvimento das competências empreendedoras de menor presença nos empreendedores, especialmente aquelas que dizem respeito à capacidade competitiva do empreendedor (proatividade) quanto de capacidade de crescimento e expansão dos negócios (controle, coordenação e rede de contatos). Na promoção 
de políticas públicas, é importante levar em consideração o fomento de ações que despertem o interesse do empreendedor, no sentido de conscientizá-lo de que o desenvolvimento de tais competências irá agregar valor ao seu negócio.

\section{Referências}

ANTONELLO, C. S. A metamorfose da aprendizagem organizacional: Uma revisão crítica. In: RUAS, R. L.; ANTONELlO, C. S.; BOFF, L. H. (Org.). Os novos horizontes da gestão: aprendizagem organizacional e competências. Porto Alegre: Bookman, 2005, p. 12-33.

AQUINO, C. O Empreendedor e o Empresário. In: Anais do RH Brasil, São Paulo, 1987.

BITTENCOURT, C. C. Gestão de competências e aprendizagem nas organizações. São Leopoldo/RS: Unisinos, 2005.

BOYATZIS, R. E. The competent Manager. New York: John Wiley \& Sons, 1982.

BRASIL, 2006. Lei Complementar 123, de 14 de dezembro de 2006. Institui o Estatuto Nacional da Microempresa e da Empresa de Pequeno Porte. Diário Oficial da União. Brasília, 14 dez. 2006.

CHEETHAM, G.; CHIVERS, G. Towards a holistic of professional competence. Journal of European Industrial Training, v. 20, n. 5, p. 20-30, 1996.

CNC. Avanços importantes para as micro e pequenas empresas 2017 - 2018. Rio de Janeiro, 2017.

COOLEY, Lawrence. Entrepreneurship training and the strengthening of entrepreneurial performance. Final Report. Contract No. DAN-5314-C-00-3074-00. Washington: USAID, 1990.

COOLEY, L. Seminário para fundadores de empresa. Manual del Capacitador. Washington: MSI, 1991.

DIAS, T. R. F. V.; NARDELLI, P. M.; VILAS BOAS, A. A. Competências empreendedoras: Um estudo sobre os empreendedores ganhadores do prêmio TOP Empresarial. In: ENCONTRO DE ESTUDOS SOBRE EMPREENDEDORISMO E GESTÃO DE PEQUENAS EMPRESAS, 5, 2008. São Paulo. Anais... São Paulo/SP: EGEPE, 2008.

DEMING, W.E. Os 14 pontos da Qualidade. Rio de Janeiro. Publicações Diversas, 1998.

DOLABELA, F. O segredo de Luisa. Uma idéia, uma paixão e um plano de negócios: como nasce o empreendedor e se cria uma empresa. São Paulo: Cultura, 1999. 
DORNELAS, J.C.A. Empreendedorismo: transformando ideias em negócios. 5ed. Rio de Janeiro: Empreende / LTC, 2014.

DRUCKER, P. Inovação e espírito empreendedor: prática e princípios. São Paulo: Pioneira, 1987.

DUTRA, J. S. Competências: conceitos e instrumentos para gestão de pessoas na empresa moderna. São Paulo: Gente, 2004.

ELIAS, N. Estudos sobre a gênese da profissão naval: cavalheiros e tarpaulins. Mana, v. 7, n. 89, p.116, 2001.

FJP - FUNDAÇÃO JOÃO PINHEIRO. Produto Interno Bruto dos Municípios de Minas Gerais: 2015. Fundação João Pinheiro, Diretoria de Estatística e Informações. - Belo Horizonte: FJP, 2017.

GEFROY, F.; TIJOU, R. Le management des competences dans les enterprises europénnes: les différentes approaches. Paris: INSEP Consulting, 2002.

GOMES, A. F.; SANTANA, W. G. P. \& ARAÚJO, U. P. "Empreendedorismo Feminino: O Estado-da-arte". Anais do Encontro da ANPAD. 33. São Paulo, 2009.

HISRICH, R. D.; PETERS, M. P. Empreendedorismo. Porto Alegre: Bookman, 2004.

JURAN, J.M. Controle da Qualidade - Conceitos, Políticas e Filosofias da Qualidadevol.1- São Paulo. McGrawHill Ltda, 1992.

KETS DE VRIES, M. F. R. Organizational Paradoxes: Clinical approaches to management. Londres: Routledge, 1995.

LE BOTERF, G. Desenvolvendo a competência dos profissionais. Porto Alegre: Artmed, 2003.

LEITE, Roberto C. De executivo a empresário: como realizar o seu ideal de segurança e independência. Rio de Janeiro: Campus, 1998.

LENZI, F. C. Os empreendedores corporativos nas empresas de grande porte dos setores mecânico, metalúrgico e de material elétrico/comunicação em Santa Catarina: um estudo da associação entre tipos psicológicos e competências empreendedoras reconhecidas. 126f. Tese (Doutorado em Administração). Universidade de São Paulo. Faculdade de Economia, Administração e Contabilidade, 2008. 
LESTER, D.L.; PARNELL, J.A.; CARRAHER, S. Organizational life cycle: a five stage empirical scale. The International Journal of Organizational Analysis, Bingley, v.11, n.4, p.339-354, Sept./Dec. 2003.

LONGEN, M. T. Um modelo comportamental para o estudo do perfil do empreendedor. Florianópolis-(SC), 1997. Dissertação (Mestrado Em Engenharia de Produção). Universidade Federal de Santa Catarina.

MALHOTRA, Naresh K. Pesquisa de Marketing: Uma orientação aplicada. 4 ed. Porto Alegre, Bookman, 2006.

MAN, T. W. Y., \& LAU, T. (2000). Entrepreneurial competencies of SME owner/manager in the Hong Kong services sector: a qualitative analysis. Journal of Enterprising Culture, 8(3), 235-254, 2000.

MCCLELLAND, D.C. The achievement society. Princeton, N.J: Van Nostrand Co, 1961.

McCLELLAND, D. C. The Achieving Society. New York: Free Press, 1967.

McCLELLAND, David Clarence. A sociedade competitiva realização e progresso social. Expressão e Cultura, 1972.

McCLELLAND, D. C. Human Motivation. New York: Cambridge University Press, 1987.

REGO, A.; LEITE, E. Motivos de sucesso, afiliação e poder: um estudo de avaliação do constructo no Brasil. Estudos de Psicologia, Brasília, v.18, n.1, p. 185-191, 2002.

SCHUMPETER, J. A. A Teoria do Desenvolvimento Econômico. São Paulo: Nova Cultural, 1982.

SEBRAE - Serviço de Apoio às Micro e Pequenas Empresas. Definição de porte de estabelecimentos segundo $o$ número de empregados. Disponível em: <https://m.sebrae.com.br/Sebrae/Portal\%20Sebrae/UFs/SP/Pesquisas/MPE_conceito_empreg ados.pdf> Acesso em: 04 abr. 2019.

SHAPERO, A. The Role of Entrepreneurship in Economic Development at the Less ThanNational-Level. Office of Economic Research, Economic Development Administration,U.S. Department of Commerce, January, 1977.

SNELL, R.; LAU, A. Exploring local competences salient for expanding small business. Journal of Management Development, v. 13, n. 4, 1994.

SPENCER, L.M.Jr., \& SPENCER,S.M. Competence at work: models for superior performance. New York: John Wiley, 1993. 
STROBINO, M. R. C. \&TEIXEIRA, R. M. (2014). "Empreendedorismo Feminino e o Conflito Trabalho-Família: Estudo de Multicasos no Setor da Construção Civil da Cidade de Curitiba". Revista Administração, USP, São Paulo, 49(1):1-18. jan./fev./mar.

WEBER, M. A ética protestante e o espírito do capitalismo. São Paulo: Pioneira, 1989. 